\title{
Fixed drug eruption to sitagliptin
}

\author{
Mrinal Gupta ${ }^{1 *}$ and Anish Gupta ${ }^{2}$
}

\begin{abstract}
Fixed drug eruption is a common adverse effect seen with various drugs notably antibiotics, antiepileptics and non-steroidal anti-inflammatory drugs. Herein we report a case of Sitagliptin induced fixed drug eruption in a 46 year old female who developed circumscribed, erythematous macules all over the body within one week of initiation of Sitagliptin. The lesions resolved with residual hyperpigmentation on cessation of the drug. The diagnosis was confirmed by an oral provocation test which led to a reactivation of the lesions. To the best of our knowledge, this is the first case of fixed drug eruption to Sitagliptin reported in the literature.
\end{abstract}

Keywords: Sitagliptin, Fixed drug eruption, Oral provocation test

\section{Background}

Fixed drug eruption (FDE) is a common cutaneous adverse effect seen with a wide array of drugs like antimicrobials, antiepileptics and non-steroidal anti-inflammatory drugs. FDE is characterized by well circumscribed, erythematous muco-cutaneous macules that can at times develop as early as 30 minutes after exposure to the causative drug, healing with residual hyperpigmentation and recurring at the same site upon subsequent exposure to the same drug. Sitagliptin is a novel antihyperglycemic agent belonging to the class of dipeptidyl peptidase IV inhibitors, which is used as a second line drug for the management of type II diabetes mellitus [1]. Herein we report a case of FDE due to Sitagliptin in a 46 year old female which, to the best of our knowledge, is the first case to be reported in the literature.

\section{Case presentation}

A 46 year-old woman presented in our centre with a three day history of multiple red colored skin lesions which were progressive and were associated with itching and burning sensation. On taking the detailed history, it was revealed that the patient had been suffering from type II diabetes mellitus for the past three years and was being managed with tablet metformin $500 \mathrm{mg}$ twice daily, but one week prior to the onset of skin lesions the patient was also started on tablet Sitagliptin $50 \mathrm{mg} /$ day by her physician in view of the poor glycemic control.

\footnotetext{
* Correspondence: drmrinalgupta@yahoo.com

'Sudhaa Skin Centre, Jammu 180019, India

Full list of author information is available at the end of the article
}

After the sixth dose of Sitagliptin, patient noticed multiple circumscribed, reddish lesions over the lips and hands which were associated with burning sensation, which over the next two days progressed to involve the trunk and lower extremities. There was no history of any other drug intake prior to the eruption or any similar lesions in the past. On muco-cutaneous examination, multiple circumscribed erythematous and hyperpigmented round macules were present over the lips, trunk and the extremities whereas the oral and genital mucosae showed the presence of well defined erosions (Figure 1). Nails and hair examination revealed no abnormality. Laboratory tests, including full blood count and biochemistry profile including liver and renal functions, were within normal limits, except for blood glucose, with a value of $167 \mathrm{mg} / \mathrm{dl}$. A skin biopsy was performed and the histopathological examination revealed a dense band like lymphocytic infiltrate, perivascular inflammatory infiltrate, eosinophils and increased pigment incontinence suggestive of fixed drug eruption (Figure 2). At this junction, a diagnosis of FDE was made and all the drugs were discontinued and the patient was started on Prednisolone $40 \mathrm{mg} /$ day and Glimepride. Five days after initiation of oral corticosteroids, the lesions subsided with residual hyperpigmentation. Two weeks later, oral provocation was done, after taking informed consent, and initially metformin was given in full therapeutic dose but no recurrence was observed. After another two weeks, patient was administered Sitagliptin $50 \mathrm{mg}$ and within six hours of administration, there was recurrence of lesions in the form of itching and erythema over the residual pigmented 


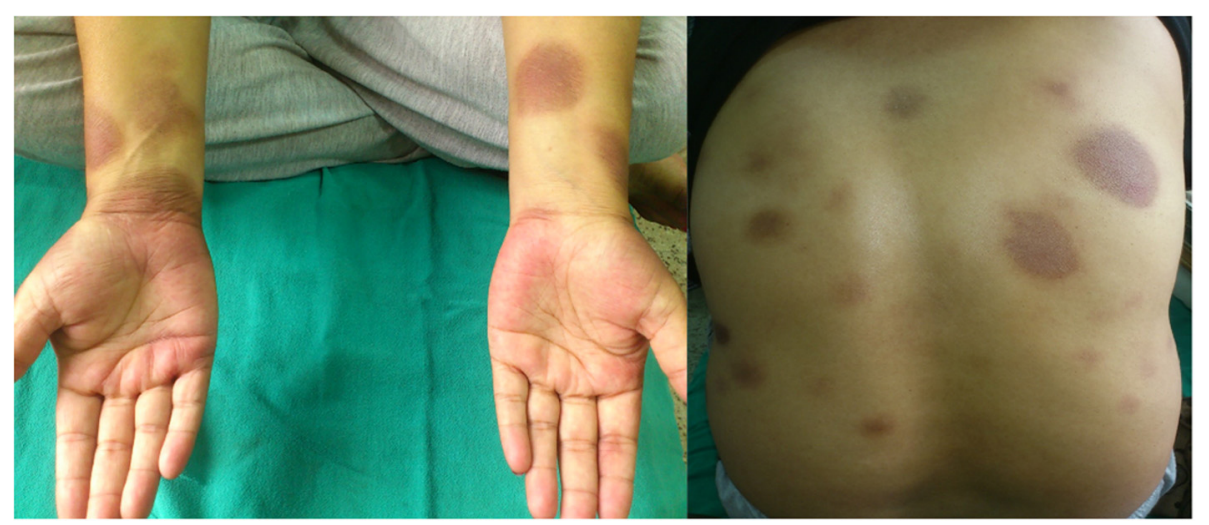

Figure 1 Fixed drug eruption involving the trunk and extremities.

lesions (Figure 3). The patient was again started on a short course of oral corticosteroids and antihistamines which led to clearance of lesions. Causality assessment was carried out using the Naranjo's scale and the World Health Organization (WHO)-Uppsala Monitoring centre (UMC) Criteria after which we came to a conclusion that Sitagliptin was the "probable" (Naranjo's score 6) cause of this adverse drug reaction [2,3]. Keeping in view her medical history and the nature of lesions, a diagnosis of FDE secondary to Sitagliptin was made and the patient was counseled regarding further avoidance of the drug.

\section{Discussion}

Sitagliptin is a newly developed oral hypoglycemic drug for the management of type II diabetes mellitus belonging to the class of dipeptidyl peptidase (DPP)-IV inhibitors, approved by the US Food and Drug Administration in 2006. Apart from systemic adverse effects like hypoglycemia, gastrointestinal effects, pancreatitis, respiratory side effects like nasopharyngitis and upper respiratory tract infections, Sitagliptin has been reported to induce a

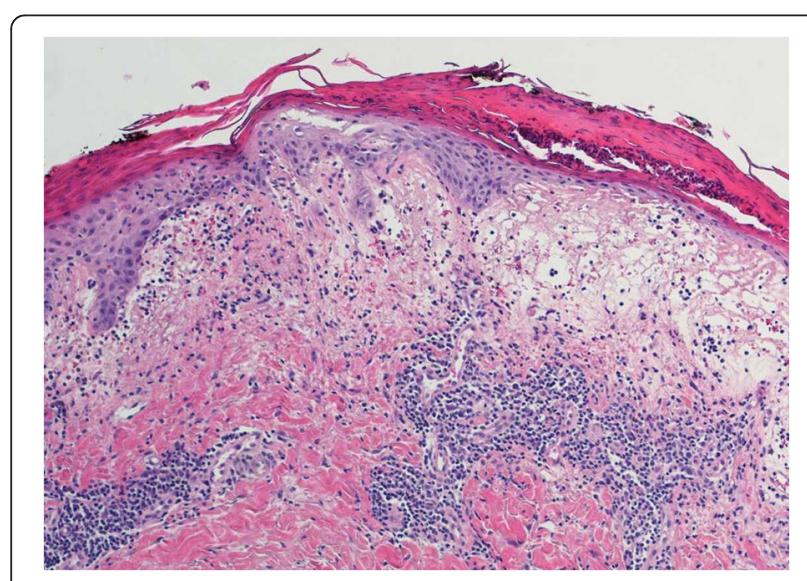

Figure 2 Histopathology (H\&E) showing band like inflammatory infiltrate, perivascular infiltrate and pigment incontinence. wide array of cutaneous adverse effects including psoriasiform eruption, maculopapular rash, Stevens Johnson syndrome, toxic epidermal necrolysis, anaphylaxis, cutaneous vasculitis, bullous pemphigoid, photosensitivity and angioedema on co-administration with ACE inhibitors [1,4-7]. A thorough search of literature could not reveal any case of FDE due to Sitagliptin till date.

FDE is a type of delayed hypersensitivity reaction mediated by $\mathrm{CD}^{+}$T-cells in which the causative drug acts as a hapten, which induces sensitization and development of sensitized $\mathrm{CD}^{+} \mathrm{T}$-cells, which get activated on re-exposure to the offending drug [8]. Although clinical history remains the mainstay of diagnosis, patch tests and drug challenge tests are also helpful and can be used

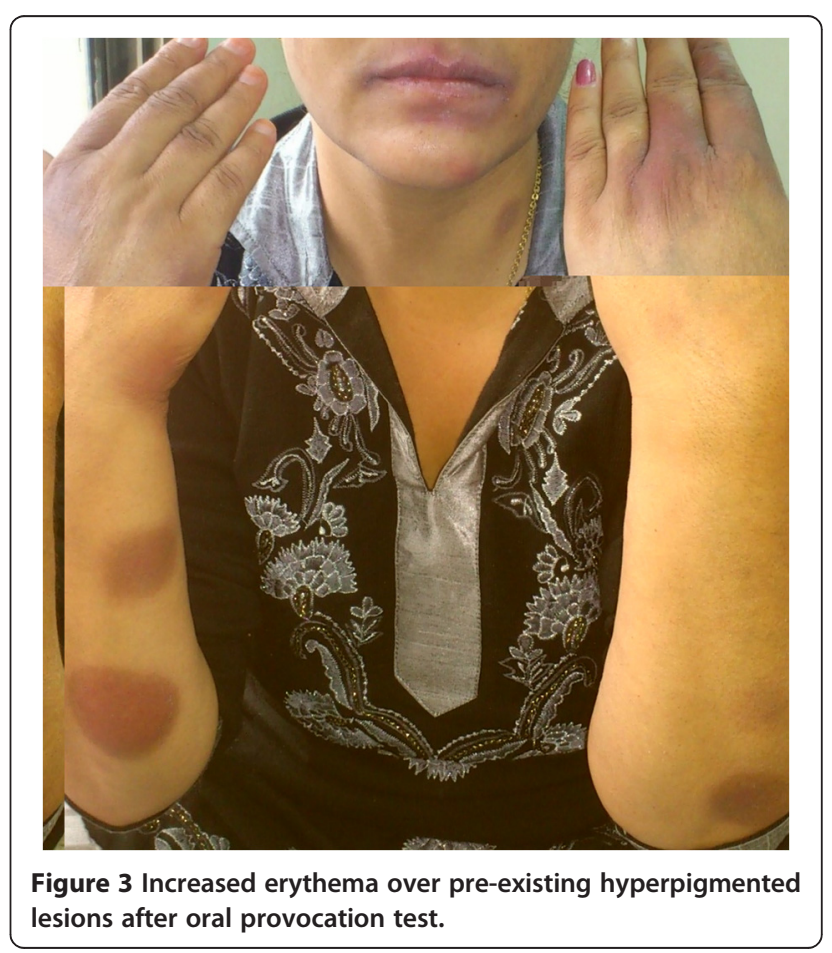


for a more objective diagnostic approach. Patch tests have been found useful in the diagnosis of FDE especially when applied at the previously affected sites. Drug challenge test are the most accurate diagnostic tool for the diagnosis of FDE which can be performed either by starting with a low dose of suspected drug followed by gradual escalation or by starting with the full therapeutic dose at once. A lymphocyte transformation test is a laboratory test for the diagnosis of delayed drug hypersensitivity especially maculopapular drug rash, but have been found useful in FDE also [9]. These tests are of importance, both for the confirmation of diagnosis as well as for the identification of causative drug. Discontinuation of the offending drug forms the mainstay of treatment and may be the only treatment required for mild cases but severe cases may require topical and systemic corticosteroids and antihistamines. Patient education and counseling regarding the avoidance of the offending drug or its derivatives to prevent recurrences constitute an important aspect of management.

\section{Conclusion}

In conclusion, Sitagliptin is a new drug commonly being used for the management of type II diabetes mellitus; henceforth adverse effects caused by it are still not fully known. Cutaneous adverse effects have been reported with Sitagliptin but this is the first case of FDE reported with it. The healthcare providers should be fully aware of the various adverse effects of the drug in order to prevent recurrences and for rapid diagnosis and proper management of the same.

\section{Consent}

Written informed consent was obtained from the patient for publication of this Case report.

\section{Competing interests}

The authors declare that they have no competing interests.

\section{Authors' contributions}

MG gave the idea and designed the study and did the investigations and follow up of the patient. AGdrafted the manuscript and edited the article. Both authors have read and approved content of the article.

\section{Acknowledgements}

We gratefully thank the patient and her family for consenting to publication of this study.

\section{Author details}

${ }^{1}$ Sudhaa Skin Centre, Jammu 180019, India. ${ }^{2}$ Acharya Shri Chander College of Medical Sciences, Jammu 180019, India.

Received: 18 January 2015 Accepted: 7 March 2015

Published online: 25 March 2015

\section{References}

1. Desai S, Brinker A, Swann J, Iyasu S. Sitagliptin associated drug allergy: review of spontaneous adverse event reports. Arch Intern Med. 2010;170:1169-71.
2. Naranjo CA, Busto U, Sellers EM, Sandor P, Ruiz I, Roberts EA, et al. A method of estimating the probability of adverse drug reactions. Clin Pharmacol Ther. 1981;30:239-45.

3. The use of the WHO-UMC system for standardized case causality assessment [monograph on the Internet]. Uppsala: The Uppsala Monitoring Centre; 2005. Available from: www.who-umc.org/Graphics/24734.pdf.

4. Stricklin SM, Stoecker WV, Rader RK, Hood AF, Litt JZ, Schuman TP. Persistent edematous-plaque photosensitivity observed with sitagliptin phosphate (Januvia). Dermatol Online J. 2012;18:9.

5. Skandalis K, Spirova M, Gaitanis G, Tsartsarakis A, Bassukas ID. Drug-induced bullous pemphigoid in diabetes mellitus patients receiving dipeptidyl peptidase-IV inhibitors plus metformin. J Eur Acad Dermatol Venereol. 2012;26:249-53.

6. Nakatani K, Kurose T, Hyo T, Watanabe K, Yabe D, Kawamoto T, et al. Druginduced generalized skin eruption in a diabetes mellitus patient receiving a dipeptidyl peptidase-4 inhibitor plus metformin. Diabetes Ther. 2012;3:14.

7. Tanaka K, Ogawa Y, Shimada S. Drug eruption caused by sitagliptin, a dipeptidyl peptidase-IV inhibitor. J Dermatol. 2012;39:726-8.

8. Shiohara T. Fixed drug eruption: pathogenesis and diagnostic tests. Curr Opin Allergy Clin Immunol. 2009;9:316-21.

9. Jung JW, Cho SW, Kim KH, Min KU, Kang HR. Clinical features of fixed drug eruption at a tertiary hospital in Korea. Allergy Asthma Immunol Res. 2014;6:415-20.

\section{Submit your next manuscript to BioMed Central and take full advantage of:}

- Convenient online submission

- Thorough peer review

- No space constraints or color figure charges

- Immediate publication on acceptance

- Inclusion in PubMed, CAS, Scopus and Google Scholar

- Research which is freely available for redistribution 